\title{
Cinémas
}

Revue d'études cinématographiques

Journal of Film Studies

\section{Hames, Peter (ed). Dark Alchemy. The Films of Jan \\ Svankmajer. Westport: Greenwood Press, 1995, 208 p.}

\section{Charles Jodoin-Keaton}

Volume 8, numéro 1-2, automne 1997

Cinéma et mélancolie

URI : https://id.erudit.org/iderudit/024752ar

DOI : https://doi.org/10.7202/024752ar

Aller au sommaire du numéro

Éditeur(s)

Cinémas

ISSN

1181-6945 (imprimé)

1705-6500 (numérique)

Découvrir la revue

Citer ce compte rendu

Jodoin-Keaton, C. (1997). Compte rendu de [Hames, Peter (ed). Dark Alchemy.

The Films of Jan Svankmajer. Westport : Greenwood Press, 1995, 208 p.]

Cinémas, 8(1-2), 215-219. https://doi.org/10.7202/024752ar d'utilisation que vous pouvez consulter en ligne.

https://apropos.erudit.org/fr/usagers/politique-dutilisation/ 
HAMES, Peter (ed). Dark Alchemy. The Films of Jan Svankmajer. Westport: Greenwood Press, 1995, 208 p.

Il n'est pas facile de classer les films de Jan Svankmajer, qui a toujours refusé de s'associer à un genre (Jiri Trnka et le cinéma d'animation) ou à un mouvement de cinéastes (la Nouvelle Vague tchèque). Le livre Dark Alchemy: The Films of Jan Svankmajer, dont la rédaction est dirigée par Peter Hames et qui a exigé la collaboration de divers auteurs (Peter Hames, Michael O'Pray, Roger Cardinal et Frantisek Dryje), aborde l'œuvre du cinéaste tchèque par le biais des diverses influences qui l'ont profondément marqué. De l'avant-garde au surréalisme tchèques, du roman gothique du XviII siècle au maniérisme de la Renaissance, autant de sujets qui donnent à l'œuvre toute son originalité, mais qui rendent la lecture du livre un peu difficile tant la matière est condensée. Il faut dire qu'un corpus de films aussi riche, si soudainement révélé dans son ensemble après la chute du communisme, exige de notre part un certain rattrapage. C'est dans cette perspective que Peter Hames, dans le premier chapitre du livre, situe le lecteur en faisant un survol des grands courants artistiques du XXe siècle en Tchécoslovaquie, afin de situer le lecteur, et souligne le rôle déterminant joué par l'avant-garde tchèque.

Peu après la naissance de la Tchécoslovaquie en 1921, l'artiste théoricien Karel Teige fonda le groupe Devetsil, qui devint rapidement un lieu de convergence artistique. Un mouvement fut baptisé "poétisme", qui s'opposait aux conventions artistiques de l'époque et prônait un retour à la "force magique du monde réel ». Ce fut une époque d'effervescence culturelle au cours de laquelle plusieurs artistes voyagèrent à l'étranger et vinrent aussi de l'étranger (Apollinaire, Breton, Éluard). Des 
liens serrés se créèrent avec le groupe surréaliste de Paris auquel Teige et le poète Viteslav Nezval s'associèrent. Reliant le poétisme à la psychanalyse et aux mécanismes créateurs du subconscient, Nezval fonda, en 1934, le premier groupe surréaliste de Prague, qui existe encore aujourd'hui. Peter Hames souligne bien l'importance de cette avant-garde tchèque, qui toucha autant la peinture (Toyen, Styrsky) que la poésie et le théâtre (le duo satirique Voskovec et Werik) et qui établit pour les artistes des générations suivantes une forte tradition expérimentale. Dans les années cinquante, c'est Jiri Trnka qui innove dans le cinéma d'animation tandis qu'Alfred Radok fonde Laterna Magika (invité à l'Expo 67 de Montréal ) et innove à la scène en y intégrant des images projetées sur écran. C'est ce goût pour l'expérimentation qui se reflète dans la Nouvelle Vague du cinéma tchèque des années soixante où se réunissent de jeunes cinéastes comme Jiri Menzl, Vera Chytilova et Milos Forman dont les films expriment les aspirations d'une jeunesse contrainte à vivre sa fougue sous un système totalitaire. Même si Jan Svankmajer débute au cinéma à cette époque et que son film, Le Jardin (1968), appartient au registre historique de la Nouvelle Vague, celui-ci dit s'être vite éloigné des préoccupations esthétiques et politiques de ce mouvement. Quoi qu'il en soit, Pater Hames a raison de souligner le caractère expérimental et anti-conformiste particulier à l'art tchèque et dont Svankmajer est aujourd'hui un des grands praticiens.

Dans le deuxième chapitre du livre intitulé "Jan Svankmajer: A Mannerist Surrealist", Michael O'Pray, un des organisateurs de la rétrospective sur Svankmajer organisée au pays de Galles en 1992, se penche sur le contenu maniériste dans les films du cinéaste. Le maniérisme est un courant artistique du XVI siècle, qui s'est beaucoup développé dans la cour des empereurs habsbourgeois Maximilien II et Rudolph II (ce dernier s'est installé à Prague). L'artiste italien Arcimboldo était d'ailleurs employé comme conservateur des collections impériales chez ce dernier. O'Pray fait remarquer que le terme " maniériste " sousentend aujourd'hui une "manière facile" d'impressionner par des effets ingénieux et gratuits. On a souvent cherché à catégoriser les films de Svankmajer en les classant d'abord dans une 
période maniériste et ensuite dans une période proprement surréaliste où l'artiste intègre de façon consciente le fruit de certaines recherches surréalistes, dont ses expériences dans le domaine du tactilisme des années soixante-dix. Il est vrai que les films de Svankmajer contiennent beaucoup d'effets maniérés. La main du cinéaste sait tout animer, des marionnettes bigarrées dans La Maison des petits cercueils (1966) à la glaise hantée dans La Chute de la maison Usher (1980) ou à l'amalgame d'objets et d'aliments se réduisant en compost dans Les Possibilités $d u$ dialogue (1982). Ce qui impressionne le plus souvent le spectateur sont les trucages d'animation dont Svankmajer exploite les techniques au point d'en rendre l'appréciation épuisante.

Mais Michael O'Pray se questionne sur le sens original du mot "maniérisme", révisant ce qui, au XVI ${ }^{e}$ siècle, était un courant artistique qui se voulait une alternative aux valeurs classiques dominantes de la Renaissance. Le maniérisme évoque une tension provoquée par la relation dynamique entre l'ordre de la structure et le désordre du contenu, entre le littéral et l'allégorique. C'est ce qu'on retrouve dans les assemblages d'Arcimboldo où, par exemple, les saisons sont représentées par des profils humains composés de fruits et de légumes ou de pièces d'artillerie. Le matière surréaliste des films de Svankmajer s'organise souvent autour d'une structure à trois chapitres (Historia Naturae, 1967, Les Possibilités du dialogue et Nourriture, 1992, etc.) et laisse chez le spectateur l'impression durable d'un chaos minutieusement calculé. O'Pray note que la tension inhérente au maniérisme et son caractère provocateur s'apparentent à la nature subversive du surréalisme et que plus de liens que de différences entre ces deux courants artistiques sont à noter, surtout dans les films de Svankmajer. Il est donc difficile et inefficace de vouloir placer les films de Svankmajer dans l'une ou l'autre de ces catégories.

Dans un troisième chapitre du livre, Roger Cardinal s'intéresse à la place prédominante qu'occupent les objets dans les films de Svankmajer. Véritable alchimiste de l'animation, Svankmajer peut extraire d'une écorce inerte les pulsions cachées de ses propres plaisirs libidineux en trompant toutes les règles de la rationalité. Il possède l'acharnement du collectionneur, ce qui 
le relie une fois de plus à Arcimboldo et ses cabinets de curiosités, et il bonde ses films d'objets fripés, déchirés, éculés, dont l'expressivité repose dans l'usure visible que l'animateur leur fait subir suite au combat sans pardon qu'ils livrent contre la logique et la fonction qu'on leur attribue quotidiennement. Comme si la matière première des choses possédait déjà une expression fantastique qui surpasse toute rationalité. C'est cet ensorcellement des objets qui rend les courts métrages de Svankmajer (surtout les premiers) si surprenants, comme Jeux de Pierre (1965), Une semaine tranquille dans la maison (1969), films auxquels Roger Cardinal fait référence en détail en n'oubliant pas de citer L'Ossuaire (1970) où, pour la première fois, le cinéaste évite les techniques d'animation. Car la matière filmée dans L'Ossuaire est déjà ré-animée par des forces incantatoires. Les milliers d'ossements humains minutieusement agencés dans l'ossuaire de Kutna Hora en Bohème orientale étant figés dans leur pose macabre, Svankmajer ne saurait mieux nous "é-mouvoir " qu'en filmant l'immobilité même de ces débris humains devenus artifices.

La quatrième partie du livre nous offre une entrevue avec Jan Svankmajer qui discute de sa formation, de surréalisme, de ses films et des relations de travail qu'il entretient avec ses collaborateurs, dont sa femme Eva Svankmajerova, elle-même peintre et écrivaine surréaliste. Vient ensuite pour clore, le chapitre final du livre intitulé "The Force of the Imagination" de Frantisek Dryje, membre du Groupe surréaliste de Prague dont fait partie Svankmajer, qui dit beaucoup profiter des critiques du groupe auquel il soumet chacun de ses films. Dryje incorpore des interventions écrites de divers membres du groupe (ce qui rend l'article un peu difficile à suivre) dont sa figure de proue, Vratislav Effenberger, poète et théoricien encore mal connu du public étranger. Dryje donne aussi une analyse intéressante sur le goût du macabre chez Svankmajer et l'influence du gothique dans son ceuvre, notamment le roman gothique du XVIII ${ }^{\mathrm{e}}$ siècle dont il emprunte à l'écrivain Horace Walpole le roman Le Château d'Otranto (1973-79). Souhaitant donner aux films de Svankmajer une vue d'ensemble, Dryje distingue l'influence du gothique classique ou littéraire (Le Château 
d'Otranto), du gothique fantastique (La Pendule, le puits et l'espoir, 1983, inspiré de Poe et de Villiers de l'Isle Adam), du gothique burlesque (la sauvagerie des marionnettes dans $L a$ Maison des petits cercueils, le jeu répétitif des dessins dans Et Cetera, 1966, le monde destructeur de l'enfance dans Jabberwocky, 1971, tiré du poème de non-sens de Lewis Carroll) et finalement du gothique réaliste, où l'univers macabre des lieux tels quels suscite la frayeur et l'angoisse (dans La Chute de la maison Usher, 1980, et L'Ossuaire, 1970). Dryje propose librement un schéma qui ne tient pas du tout compte de la chronologie des films de Svankmajer mais qui les organise selon un critère esthétique cohérent. Sans schématiser, son approche offre un aperçu clair et global d'une œuvre cinématographique autrement difficile à aborder dans son ensemble.

Étant le fruit d'une collaboration à quatre, le livre Dark Alchemy. The Films of Jan Svankmajer offre une bibliographie très intéressante et exhaustive. Une filmographie complète des courts et longs métrages de Svankmajer est aussi incluse. Elle doit cependant être mise à jour, car Svankmajer a réalisé depuis son troisième long métrage, Les Conspirateurs du plaisir, sorti l'année dernière, et son quatrième, L'Homme de bois (titre provisoire), doit sortir sous peu. Dark Alchemy, The Films of Jan Svankmajer demeure incontestablement l'étude la plus complète des films du cinéaste dont l'œuvre, peu suivie par les médias, ne cesse de grandir. 